report is devoted to a study of the fauna associated with the sites, and the third to some skulls from the Woodland-culture mound. The value of the report lies in supplementing our information about the distribution of the cultures found, and is enhanced by a map and classified list of archæological sites in Illinois at the beginning. It would have been easier to follow had the descriptions of sites been arranged in some intelligible kind of order, segregating those of various cultures. The introduction says that it was impossible to include the maps and diagrams of the sites; the inclusion of at least some of them would undoubtedly have been an advantage.

3 ?

\section{Mineral-insulated Metal-sheathed Conductors}

IN a recent inpliblisted paper (J. Inst. Elec. Eng., 93, Part 2 J 34, 1946), Messrs. F. W. Tomlinson and H. Whight discuss the development and uses

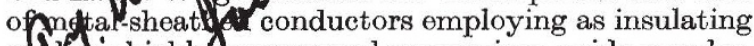
nf phim highly ompressed magnesium oxide powder. In consequende of the high-temperature stability and the good insulating properties of this material, these conductors have found wide application as electrical heating elements in radiant boiler-plates and as power supply cables in circumstances where the avoidance of fire-risk is of special importance, or where the ambient temperature or atmospheric conditions are too severe for other types of electric cable. The low dielectric loss exhibited by magnesium oxide at very high frequencies, combined with the other advantageous characteristics mentioned, has also enabled specially designed cables to be used for certaip important radar purposes.

\section{Status of Translations and Translators}

IN his pam "On Translations", reprinted from

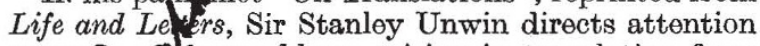
to sop of he problems arising in translation from one Itny age to another, and to inadequacies and inquumies still encountered, although during the pas forty years the quality of translations into Endl sh and the status of translators have steadily improved (London: Allen and Unwin, Ltd. Pp. 8. 6d. net). Sir Stanley emphasizes that first and foremost the translator should be adequately paid, and payment for translation should be a first charge, taking precedence over the author's remuneration. The translator's name should always be given, provided it is his (or her) exclusive work, and it should be a universal practice to print, on the back of the title-page of any translation, the title of the original work. The best remedy for 'mistranslation and for deliberate tampering with the text is informed criticism; bad translations should be denounced. Authors should help by giving preference to publishers who take pride in the quality of their translations and maintain a high standard; but while the publication of translations is in general more speculative than the issue of original work, Sir Stanley does not agree that the publication of translations should be financed by governments. If, however, for commercial reasons any work of outstanding importance had remained untranslated for, say, five years, governments would be well advised to offer to bear the cost of translation, if a publisher was willing in that event to produce the work at his own risk and expense. The pamphlet also includes some notes on "Our Universal Language", which stress the importance of the new demand for British" books.

\section{Museums of To-morrow}

Dr. D. A Allan's presidential address on the occasion of he Muserums Association's annual conference an -Brightgy ths year is reported in full in the Mrsetms. Jownal of August. Under the title, "Avatums- it atis Mutandis", Dr. Allan advocates ro teaching in the muserm and less congestion of ellibits, and he is of the opinion that museums should not strive to increase already immense collections. "To perform its function adequately," he says, "each museum, large or small, must adopt a plan and work it out. It is not enough merely to tidy-up a museum; it must be put into working order; it must show less and teach more." He also appeals for the establishment of special museums to demonstrate the history and applications of British mechanical invention and engineering, mining and agrieulture, and looks for the further development of folk museums so that there may be one to each distinctive region of the British Isles.

\section{Economics of International Trade}

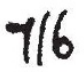

IN Pamphle No. 7, "International Trade", in the "Looking" Erwward" series issued by the Royal Instityte International Affairs, G. A. Duncan point ofit arst that international trade between two contcies really means a multitude of independent tfapetions linked by nothing more serious than the adedent that their participants happen to live in two politically defined areas; hence, while all the problems, spurious as well as real, would still be there if the world "was politically unified, they would not be linked up with political units and political power. He then attempts to set out the nature of the principal questions that arise on the assumption that one State, one supreme political government, embraces the whole earth. The complications introduced by the existence of sixty-odd sovereign and independent States are then considered, and the conditions precedent to the revival and growth of international trade in the post-war world are indicated. International trade, Mr. Duncan argues, consists of an economic substratum overlaid by a political scum. The economic reality is that the real welfare of the world's human population is a function of the optimum use of its diversified resources-mineral, vegetable, animal and: human-under contemporary conditions of technical knowledge.

The optimum pattern, according to Mr. Duncan, is not a matter of merely technical comparison, but of economic balancing, taking into account differing valuations of resources in differing areas, and the correct distribution can only be determined by the empirical method of competition, which continually presents the dilemma of choice between immediate, localized and vocal loss, and more distant, diffused and inarticulate gain. The competitive process can only yield its dividends when it is allowed to proceed so far as possible on economic grounds. The political scum consists of the arbitrary importance attached to trade crossing political frontiers and to the significance of partial calculations about its component elements; the tendency to think of international trade as trade between definable political entities instead of an arithmetical accident; and the invasion of economic problems by notions of political power and prestige. The problem for economic statesmanship in the next fow years, he concludes, is that of working out by common agreement a form and extent of political impositions upon international 